\title{
A MULTINACIONAL QUE TERCEIRIZOU SUAS TRANSAÇÕES FINANCEIRAS
}

\author{
THE MULTINATIONAL THAT OUTSOURCED FINANCIAL TRANSACTIONS
}

\author{
Recebido em 10.01.2017. Aprovado em 19.06.2017 \\ Avaliado pelo sistema double blind review \\ DOI: http://dx.doi.org/10.12712/rpca.v11i3.884
}

\section{Arnaldo Di Petta}

adi.petta@hotmail.com

Universidade Nove de Julho (UNINOVE), São Paulo/SP, BRASIL

\section{Renato Ribeiro Nogueira Ferraz}

renatobio@hotmail.com

Universidade Nove de Julho (UNINOVE), São Paulo/SP, BRASIL

\section{Cristiane Drebes Pedron}

cdpedron@gmail.com

Universidade Nove de Julho (UNINOVE), São Paulo/SP, BRASIL

\section{Resumo}

Este caso de ensino traz a história real de uma multinacional que decidiu adotar o modelo de Centros de Serviços Compartilhados (CSC) nas diferentes regiões em que atua no mundo. Além de esclarecer o que é este modelo, o caso também apresenta desafios da área de finanças global da empresa e descreve o projeto de implantação de um CSC terceirizado na América Latina. Um membro da equipe do projeto relata a tomada de decisão, os obstáculos na negociação, os acordos na fase de planejamento e, por fim, as lições aprendidas a cada etapa. O relato destas experiências serve para empresas que necessitam ajustar planos globais à realidade regional e também às unidades de negócios que precisam implantar mudanças organizacionais radicais. Serve também às empresas que estudam a implantação de um CSC para reduzir custos e melhorar serviços. O caso é recomendado para cursos de Administração e disciplinas ligadas a finanças, gerenciamento de projetos e de mudanças, visão estratégica e planejamento.

Palavras-chave: Caso de ensino. Centros de Serviços Compartilhados. CSC. Gerenciamento de Projetos. Terceirização.

\begin{abstract}
This teaching case presents the true story of a multinational that decided to adopt the Shared Services Centers (SSC) model in the different regions where it run business around the world. Beyond explaining what a SSC is, the case presents challenges faced by global finance area and describes in details the project to implement the outsourced SSC in Latin America. A project team member reports the discussions held before the decision, the barriers during the negotiation phase, highlights agreements in the definition and planning phases and, finally, reveals lessons learned in each phase. The learnings may support companies that need to adjust global plans to the regional reality, and to the business units that need to make radical organizational changes. They also serve companies studying the deployment of a CSC to reduce costs and improve services. This case is mainly recommended for courses in Administration and disciplines related to finance, project and change management, strategic vision and planning.
\end{abstract}

Keywords: Teaching case. Shared Services Centers. SSC. Project Management. Outsourcing. 


\section{Introdução}

Quais são os principais pontos a considerar para desdobrar uma estratégia global às unidades de negócios espalhadas pelo mundo? Uma estratégia global? O modelo de Centros de Serviços Compartilhados (CSC) traz benefícios? É possível terceirizar transações financeiras? O presente caso de ensino trata destas questões ao basear-se no caso real da tomada de decisão estratégica de uma multinacional no setor de cosméticos para adotar e implantar o modelo de CSC destinado a executar as transações financeiras das áreas de Contas a Receber, Contas a Pagar e Contabilidade Geral de todas as suas unidades de negócios no mundo. Em particular, destaca-se o planejamento para a implantação de um CSC terceirizado para processar as operações financeiras dos quinze países que compõem a unidade de negócios chamada América Latina.

Além dos objetivos já descritos, este caso de ensino trata também de aspectos culturais na relação de uma empresa globalizada com suas unidades de negócios localizadas na América Latina, além de destacar elementos de Administração, Gestão Estratégica, Revisão de Processos e Gerenciamento de Projetos. As decisões e definições tomadas pela empresa multinacional no âmbito global, bem como os desafios enfrentados pela direção regional de finanças desde o início deste projeto, são narradas em desdobramentos que exigiram flexibilidade, habilidades de negociação, planejamento e um intenso programa de gerenciamento de mudanças.

\section{A empresa e sua história}

O presente caso de ensino descreve a situação vivida por uma empresa multinacional de origem norteamericana que atua no setor de cosméticos. Fundada no final do século XIX, a partir de meados do século $\mathrm{XX}$, esta empresa iniciou suas operações na Europa, na Ásia e na América Latina, tendo progressivamente se instalado em quinze países da América Latina. A receptividade do mercado latino-americano foi tão positiva que no início do século XXI a maior parte de seu faturamento e de seu lucro vinha desta região. Talvez por isso, a América Latina concentrava o maior número de funcionários de finanças e também a maioria das transações financeiras, comparado ao total global da empresa. A busca pela redução de custos administrativos, pela padronização de processos e pela melhoria dos serviços levou a empresa a considerar a instalação de Centros de Serviços Compartilhados (CSC) para a área de Finanças.

\section{0 modelo de Centro de Serviços Compartilhados}

Para reduzir os custos e melhorar os serviços prestados, muitas empresas globalizadas, baseadas nos Estados Unidos, a partir do final da década de 80, passaram a adotar o modelo de Centros de Serviços Compartilhados (Bergeron, 2003; Schwarz \& Mechling, 2007). Em relação a objetivos e particularidades, CSC é a prática em que unidades de negócios de empresas decidem compartilhar serviços em vez de tê-los como uma série de funções de apoio duplicadas dentro da organização (Quinn, Cooke, \& Kris, 2000). Centralizando atividades transacionais, padronizando processos e otimizando sistemas, principalmente aqueles de Recursos Humanos (RH), Tecnologias de Informação (TI) e Finanças, este modelo permite maximizar os recursos da empresa ao realizar tarefas de cunho transacional em uma unidade com autonomia. A estrutura gerencial de um CSC é definida com os objetivos de promover eficiência, gerar valor e melhorar os serviços para os vários clientes internos da empresa, atingindo assim a redução de custo com bom nível de serviços (Schulman, Harmer, \& Lusk, 2001).

Vale lembrar que existem diversas configurações de CSCs, por exemplo: um centro localizado em uma só cidade que atenda toda a corporação globalmente, centros regionais servindo aos países que compõem determinada região geográfica, sendo esta a configuração do caso estudado em maior profundidade, e até mesmo centros locais que atendam diferentes unidades de negócios dentro de um mesmo país. Quanto ao gerenciamento, os CSCs podem ser operados de maneira própria ou ainda terceirizados, sendo que, para suportar este caso, algumas de suas características são: ao optar pela administração própria, a empresa controla a operação de acordo com suas prioridades e com sua cultura, gerencia com maior efetividade a segurança de suas informações e normalmente alcança resultados através de uma relação em mais longo prazo (Janssen \& Joha, 2006). Já terceirizando a operação, são evitados investimentos iniciais e abrevia-se o começo das atividades, tomando-se proveito do know-how do terceiro, prestador de serviços (Hayes, 2007). 


\section{Visão estratégica de finanças global e os primeiros CSCs}

Com mais de 100 anos de história, a empresa multinacional relatada neste caso de ensino, ao final da primeira década deste século, vinha buscando reduzir seus custos administrativos. Apoiada no exemplo de outras grandes corporações globalizadas, que a partir do final dos anos 80 começaram a obter benefícios significativos com a utilização de Centros de Serviços Compartilhados (CSC), a sua liderança global de finanças tomou a decisão estratégica de adotar o mesmo modelo. A ideia foi implantar seu primeiro CSC em uma das quatro regiões geográficas nas quais tinha negócios e depois expandir o modelo para as demais. Desta forma, entendia que poderia conseguir maior eficiência em suas operações financeiras, alcançar melhoria contínua em seus processos, reduzir o quadro de funcionários e, finalmente, ter um custo de operações financeiras mais competitivo.

Após estudos preliminares e quase sem divergências entre aqueles que eram os responsáveis pela tomada de decisão, a escolha inicial dos líderes de finanças global recaiu sobre a Europa, onde as operações se apoiavam em duas fábricas e três centros de distribuição para atender a quase 20 unidades de negócios. A pequena distância geográfica entre os países europeus, a existência de um sistema de informações chamado Enterprise Resource Planning (ERP), único nas unidades que compunham esta região, a padronização e relativa simplicidade dos processos bem documentados, os benefícios proporcionados pelos diferentes tratados de livre comércio e a alta qualificação e especialização da mão de obra, foram elementos que suportaram a discussão e levaram a tomada desta decisão de maneira quase que natural.

Com este objetivo definido e considerando os benefícios trazidos pela instalação de um CSC próprio, a empresa investiu recursos para a implantação de seu CSC em um país do Leste Europeu, preparando o local e a infraestrutura adequados. A instalação física já era existente, pois abrigava os profissionais que serviam às operações locais e necessitou de poucos investimentos para sua adequação. A equipe de finanças, que já executava as transações para a unidade de negócios localizada neste país, adicionou mais profissionais contratando o número suficiente para adequar o quadro de funcionários às necessidades de sua operação para toda a Europa. A liderança da operação foi entregue a um diretor e três gerentes que já pertenciam à empresa e, pelo fato de não ter ocorrido um número elevado de dispensas, a resistência ao projeto foi facilmente contornada. Vale destacar que a expressiva maioria dos funcionários que seriam dispensados nos demais países foi realocada para outras funções em suas próprias localidades. Como era de se esperar, o processo de migração das atividades dos demais países para o centro localizado no país do Leste Europeu ocorreu dentro do previsto e a implantação foi concluída em pouco mais de seis meses, transcorrendo sem problemas relevantes. Diante deste cenário e das condições favoráveis, a liderança global de finanças da empresa multinacional considerou que os resultados alcançados justificaram plenamente os investimentos.

À medida que os bons resultados do modelo de CSC eram confirmados na Europa, foram acelerados os estudos para as demais regiões. Neste sentido, as dificuldades de caráter organizacional, a existência de diferentes modelos de comercialização, a dispersão geográfica e uma certa instabilidade nos resultados comerciais da região, fizeram com que a Ásia fosse deixada como última prioridade. A escolha para a segunda região a trabalhar com o modelo de CSC deveria ser feita entre a América do Norte, região composta por apenas duas unidades de negócios com reduzido escopo de atividades, processos simples e sistema ERP único já implantado, ou a América Latina, composta por quinze unidades, grande complexidade de processos e uma enorme variedade de sistemas, pois, até então, o ERP não havia sido instalado nesta região.

É fácil concluir que, pouco tempo depois, a direção global de finanças escolheu implantar o modelo de CSC na América do Norte. Os altos custos de instalação em solo americano bem como da mão de obra local e a premência por resultados rápidos foram algumas das razões que levaram a empresa a escolher o modelo terceirizado. Para isso, foi estabelecido um processo de busca e negociação com prestadores de serviço de todo o mundo, recaindo a decisão final sobre um grande prestador de serviços indiano. $\mathrm{O}$ idioma inglês, comum a todos os envolvidos, foi um dos fatores que facilitaram a decisão, uma vez que a operação seria a partir de um centro localizado na terceira maior cidade da Índia, com abundância de mão de obra. A eliminação de posições nas equipes de finanças nos países da América do Norte não chegou a ser problemática em função do dinamismo dos mercados de trabalho locais, porém o processo de 
transição de atividades das unidades de negócios desta região para o centro de serviços localizado na Índia não transcorreu da maneira esperada, o que de início abalou de certa maneira a confiança no prestador de serviços e, por consequência, deixou instável a relação entre a empresa multinacional e o prestador de serviços. Talvez por isso, foram frequentes as queixas em relação à qualidade de serviço e avolumaram-se as disputas entre a empresa multinacional e o fornecedor indiano.

Com uma experiência muito positiva de um centro próprio na Europa e outra nem tanto com um centro terceirizado na Índia, chegava o momento de aplicar o modelo de CSC à América Latina, região que anteriormente já havia passado por algumas experiências não muito positivas em relação à implantação de projetos regionais desenvolvidos pelas funções de Supply Chain, Vendas e Marketing.

\section{América Latina e sua complexidade}

Para esta empresa multinacional, a América Latina era muito significativa. Apesar do baixo poder aquisitivo de sua população, das dificuldades tecnológicas, do ambiente extremamente complexo em relação às questões fiscais de cada país, das longas distâncias geográficas, das limitações de formação da mão de obra especializada e das altas taxas de desemprego na maioria dos países, representava a região que mais vendia e mais gerava lucros dentre as quatro regiões onde a multinacional operava. Além destes componentes sociopolíticos estruturais, vale a pena mencionar que as quinze unidades de negócios na região comportavam seis fábricas e onze centros de distribuição, sendo que, para sustentar toda esta operação, o quadro completo de funcionários de todas as funções e áreas de apoio era bem maior do que as demais três regiões, fato este que sempre chamou a atenção da alta direção global quando se desenvolviam e aplicavam os programas globais de reestruturação e redução de pessoal.

No passado, com o objetivo de diminuir o contingente de funcionários e aumentar ainda mais a lucratividade na América Latina, foram feitas algumas tentativas de implantar modelos operativos regionais de Supply Chain, porém sem sucesso. Da mesma forma, a aplicação de serviços regionalizados de Marketing não alcançou os benefícios esperados e até mesmo os estudos para uniformizar entre os países os modelos de Vendas e comercialização não foram concluídos de maneira satisfatória. Houve também uma tentativa de estabelecer os países em clusters para, de alguma maneira, tomar benefícios de escala, porém não foram alcançados resultados expressivos. Finalmente, a visão da direção da multinacional passou então a ser o estabelecimento de uma administração regionalizada no âmbito da América Latina, o que se concretizou apenas em 2004.

Focando a área de finanças, apesar de uma liderança única na região, cada unidade de negócios tinha seus próprios processos financeiros bastante complexos e pouco documentados, usando no total mais de duas centenas de aplicações e pequenos sistemas informatizados que quase não se comunicavam entre si. Este quadro, possivelmente, foi fruto do modelo operativo utilizado até os primeiros anos deste século quando não haviam ainda sido aplicados modelos operativos que tomassem benefícios da regionalização e muito menos da globalização, tais como ganhos de escala, padronização de produtos e uniformidade de processos e sistemas. Por outro lado, a inexistência de um ERP exigia de todas as unidades de negócios grande esforço para processar, documentar, registrar e conciliar contabilmente um volume de transações financeiras e operacionais que chegava a centenas de milhares todos os dias, tais como envio de pedidos, pagamento de fornecedores, recebimento de clientes e recolhimento das obrigações fiscais.

Finalmente, vale destacar que a soma de todos os profissionais de finanças trabalhando nas áreas de Contas a Receber, Contas a Pagar e Contabilidade Geral, em todos os países na América Latina, chegava a cerca de 450 pessoas, constituindo-se disparadamente no maior contingente de finanças dentre todas as quatro regiões.

\section{Um CSC de Finanças na América Latina}

Diante desse panorama, considerando as experiências anteriormente vividas pela empresa e para implementar a visão estratégica da liderança global de finanças, a primeira decisão a ser tomada seria: implantar um CSC próprio ou terceirizado? E ainda: seria possível implantar um CSC sem um ERP na região? Ou se deveria esperar a implantação do ERP para depois seguir com o plano do CSC? Em qualquer situação, seria possível implantar o projeto sem impactar os resultados da região mais lucrativa? Como administrar 
a possível eliminação de várias posições nas áreas financeiras em cada país?

\section{Primeiro passo: tomada de decisão}

A primeira definição foi alcançada avaliando os critérios indicados no Quadro 1:

Quadro 1. Comparação dos modelos de gestão

$$
\text { do CSC }
$$

\begin{tabular}{|c|c|c|}
\hline Critérios & CSC Próprio & CSC Terceirizado \\
\hline $\begin{array}{l}\text { Custo de } \\
\text { implantação do } \\
\text { projeto }\end{array}$ & $\begin{array}{l}\text { Grande } \\
\text { investimento } \\
\text { inicial }\end{array}$ & $\begin{array}{l}\text { Diluído ao longo } \\
\text { do contrato de } \\
\text { prestação de } \\
\text { serviços }\end{array}$ \\
\hline $\begin{array}{l}\text { Tempo para } \\
\text { implantação do } \\
\text { projeto }\end{array}$ & $\begin{array}{l}\text { Seria mais } \\
\text { demorado, } \\
\text { principalmente } \\
\text { pela necessidade } \\
\text { de uma nova } \\
\text { instalação física }\end{array}$ & $\begin{array}{l}\text { Mais rápido } \\
\text { instalar um CSC } \\
\text { terceirizado do que } \\
\text { um CSC próprio }\end{array}$ \\
\hline $\begin{array}{l}\text { Histórico na } \\
\text { implantação } \\
\text { de projetos na } \\
\text { região }\end{array}$ & $\begin{array}{l}\text { Projetos } \\
\text { anteriores } \\
\text { sem sucesso } \\
\text { (por falta de } \\
\text { disciplina em } \\
\text { projetos) }\end{array}$ & $\begin{array}{l}\text { Projetos de êxito } \\
\text { em outros clientes }\end{array}$ \\
\hline $\begin{array}{l}\text { Equipe para } \\
\text { gerir o projeto } \\
\text { de implantação }\end{array}$ & $\begin{array}{l}\text { Formar um } \\
\text { novo grupo de } \\
\text { trabalho com } \\
\text { conhecimento } \\
\text { específico }\end{array}$ & $\begin{array}{l}\text { Grupo existente } \\
\text { com experiências } \\
\text { anteriores }\end{array}$ \\
\hline $\begin{array}{l}\text { Localização do } \\
\text { CSC }\end{array}$ & $\begin{array}{l}\text { Com quinze } \\
\text { países na região, } \\
\text { era difícil tomar } \\
\text { uma decisão } \\
\text { meramente } \\
\text { técnica- } \\
\text { financeira }\end{array}$ & $\begin{array}{l}\text { O fornecedor } \\
\text { terceiro já teria } \\
\text { seus centros } \\
\text { instalados e não } \\
\text { haveria conflitos } \\
\text { dentro da empresa }\end{array}$ \\
\hline $\begin{array}{l}\text { Know-how na } \\
\text { operação de } \\
\text { um CSC }\end{array}$ & $\begin{array}{l}\text { Inexistente na } \\
\text { América Latina }\end{array}$ & $\begin{array}{l}\text { Consistente e } \\
\text { acumulado em } \\
\text { anos de experiência }\end{array}$ \\
\hline $\begin{array}{l}\text { Redução } \\
\text { no custo de } \\
\text { operação }\end{array}$ & $\begin{array}{l}\text { A ser buscada, } \\
\text { de acordo com } \\
\text { o business case }\end{array}$ & $\begin{array}{l}\text { Assegurada por } \\
\text { contrato }\end{array}$ \\
\hline
\end{tabular}

Após a avaliação dos critérios descritos no Quadro 1 e considerando os business cases preparados com antecedência, a equipe de finanças global tomou a decisão de adotar o modelo terceirizado, mesmo considerando a experiência um tanto quanto atribulada vivida na terceirização das atividades da América do Norte. Foi assumido também o compromisso de que as oportunidades de melhoria identificadas naquele projeto serviriam de lições aprendidas para a implantação do CSC na América Latina. A partir daí, foi constituído um grupo de trabalho com a participação, dentre outros, do principal líder de finanças da América Latina e de um alto executivo de finanças da região para atuação nos processos de definição, negociação, planejamento e implantação do projeto.

\section{Segundo passo: definição do fornecedor}

Para definir qual seria o fornecedor a prestar o serviço de transações financeiras aos países da América Latina, foi aplicado um processo global para a busca e seleção de fornecedores, sendo que as empresas indianas também participariam. Entretanto, uma das dificuldades enfrentadas por elas se referia aos idiomas português e espanhol, necessários às frequentes interações entre as pessoas de finanças dos países da região, porém não facilmente encontrados nos profissionais indianos. Desta forma, após as primeiras rodadas de seleção, dois grandes fornecedores "ocidentais" (um americano e outro europeu) restaram na concorrência com preços muito semelhantes, porém 
com duas diferenças fundamentais: o fornecedor \#1 apresentava a abordagem de redesenhar processos durante a migração de atividades das unidades de negócios na região para o CSC e também a introdução desejável de um ERP antes da transição. O fornecedor \#2 sugeria a revisão de processos somente depois de completada a migração de todas as atividades para seu centro e se dispunha a fazê-la mantendo todas as mais de duzentas aplicações tecnológicas existentes nos países. Ao término das rodadas finais de negociação, o fornecedor \#2 foi o escolhido pelo preço e também por apresentar uma abordagem que representava menor risco à operação.

\section{Terceiro passo: negociações com o fornecedor}

A partir de então, foram iniciadas as negociações com o fornecedor escolhido para explicitar as cláusulas gerais que foram apresentadas, discutidas e ajustadas durante o processo de seleção. A precariedade no registro da quantidade de transações por parte das unidades de negócios impediu que este volume fosse adotado como critério de faturamento pelos serviços. Por isso, foi necessário discutir as condições de pagamento do preço dos serviços por FTE (full time employee), sendo imprescindível também discutir o contrato de prestação de serviços e seus desdobramentos tanto no aspecto regional quanto também para cada um dos quinze países que seriam atendidos pelo fornecedor. A partir dos aspectos jurídicos do contrato, passando pelo processo e maneira de faturamento dos serviços e o devido pagamento de impostos, era também necessário detalhar as condições de funcionamento da operação, tais como horários de atendimento e níveis de serviço. Definição de penalidades em caso de falhas na entrega dos serviços, condições para a manutenção do sigilo das informações requeridas para a execução das atividades, documentos necessários à operação, estrutura de funcionamento do CSC, conformação das equipes de serviço, e os papéis e responsabilidades de cada um dos elementos dentro da relação comercial que naquele momento se iniciava, também foram objeto de negociação.

Além disso, era necessário também discutir em detalhes as atividades que seriam transferidas para o centro, identificando até onde iria a responsabilidade de cada país e a partir de onde se iniciava a responsabilidade do centro. Isso sem falar na abordagem a ser adotada para a transição de atividades, ou seja, a migração de cada uma delas, de cada um dos países, indo para o
CSC. À medida que se detalhavam estas questões, era necessário também discutir internamente como tratar este grande projeto, fazendo com que sua implantação tivesse êxito e trouxesse os resultados esperados.

\section{Quarto passo: planejamento do projeto}

Para que a transição pudesse ser planejada em detalhes, formou-se uma equipe multidisciplinar com mais cinco profissionais da multinacional, sendo que todos ficaram subordinados ao diretor que já participava das negociações. Um deles era um gerente sênior de finanças global que havia trabalhado nos projetos dos CSCs da Europa e da América do Norte. Os outros quatro trabalhavam em unidades de negócios da América Latina, sendo eles: um gerente de projetos para, junto do fornecedor, tratar da condução e dos detalhes para a implantação do projeto; um gerente especialista em finanças para trabalhar em conjunto com o fornecedor e também para ser o elo entre os líderes e equipes de finanças de cada país; um especialista em tecnologia de informação para atuar nas ações necessárias à segurança, à compatibilização e acessos aos sistemas de informação; finalmente, um profissional dedicado à comunicação, que seria responsável por identificar as audiências e preparar o conteúdo adequado, o formato adequado e a periodicidade adequada as mensagens e informações adequadas a cada tipo de audiência.

O gerente sênior trouxe as experiências da implantação desenvolvida na Europa, aportando conhecimentos em relação ao escopo de atividades migradas dos países para o centro. Além disso, exerceu papel importante na articulação junto à equipe de finanças global, principalmente nas negociações envolvendo os aspectos jurídicos do contrato. Outra contribuição importante foi em relação às oportunidades de melhoria identificadas na experiência vivida com o fornecedor indiano que prestava serviços para a América do Norte. As interfaces das atividades entre o CSC e o terceiro eram o ponto mais delicado, porém as questões de escalamento e resolução de conflitos durante a operação diária também mereceram atenção.

Ao gerente de projetos coube estabelecer, junto com a equipe do fornecedor e com o gerente especialista em finanças, a sequência de implantação e o cronograma para a transição de atividades. Seria possível fazer a transição por processos, ou seja, fazer todas as atividades dentro de Contas a Pagar para todos 
os países e depois passar às atividades de Contas a Receber e Contabilidade Geral, por exemplo. Outra opção seria fazer a transição geográfica, ou seja, por países, sendo migradas todas as atividades de todos os processos dentro do escopo para cada país ou grupo de países. Foi tomada a definição de que a abordagem geográfica seria a mais adequada, pois, além de facilitar as definições técnicas, permitiria também que os impactos de comunicação e atividades para facilitar o gerenciamento de mudanças fossem administrados da melhor maneira possível.

O gerente especialista em finanças foi o responsável por discutir com cada país e também com o fornecedor os detalhes das atividades a serem migradas para o centro. O General Statement of Work, ou seja, uma declaração geral de responsabilidades por cada atividade dentro de um processo, deveria ser desdobrado para cada país de forma a obter aprovação e apoio do líder de finanças local, permitindo a execução correta da atividade, de acordo com as particularidades de cada unidade de negócios. Além disso, seria necessário quantificar os volumes das transações por atividade e também o tempo usado para cada uma delas, resultando na decisão da quantidade de posições a serem eliminadas. A verificação da documentação e dos sistemas de informação necessários às operações também fazia parte desta avaliação técnica.

O especialista em TI desempenhou um papel importante trabalhando em conjunto com as equipes de TI dos países para levantar a utilização e as características técnicas de todas as mais de duzentas aplicações existentes na região. Além disso, trabalhou fortemente com a equipe global de TI para desenvolver mecanismos e procedimentos de segurança para proteger os acessos a cada um dos sistemas envolvidos. A quantificação do volume de informações e a capacidade das bandas de acesso e transmissão de dados foram trabalhadas em conjunto com a equipe de TI do fornecedor, de acordo com as características de cada país e seguindo as orientações e os protocolos globais da empresa.

Finalmente, o profissional dedicado à comunicação teve participação decisiva no planejamento, interagindo com todos os membros da equipe de implantação, com diferentes pessoas em diferentes níveis nas unidades de negócios e também com o prestador de serviços. Atuando junto com o gerente do projeto, prepararam um plano de gerenciamento de mudanças que contemplava uma visita a cada país envolvido, tendo diálogos abertos com líderes locais e também com as equipes de finanças que seriam afetadas pela migração de atividades para o CSC. Desta forma, seriam levantadas necessidades especiais de cada país, o que permitiria desenvolver ações específicas. Além disso, o profissional dedicado à comunicação foi responsável por identificar todas as audiências existentes no projeto e adequar a elas as mensagens referentes a cada etapa, mantendo o devido alinhamento e padronização.

Desta forma, havia então sido desenhado todo o planejamento e um plano de gestão de mudanças para que a implantação pudesse ter os riscos minimizados e viesse a ser concretizada, trazendo os resultados esperados. Porém, nem sempre os planos saem como o esperado... O que viria a ocorrer durante a transição?

\section{Notas de ensino:}

\section{Utilização recomendada}

O caso foi preparado principalmente para os cursos de graduação e pós-graduação em Administração de Empresas, Administração Estratégica e Administração de RH, especificamente em Change Management. Toca abordagens multidisciplinares de Finanças, Gerenciamento de Projetos, Gerenciamento de Mudanças, Estratégia e Planejamento em empresas multinacionais. Podem também ser desenvolvidas aplicações em cursos de capacitação em Recursos Humanos ou Gestão de Pessoas e até mesmo em Tecnologia e Sistemas de Informação.

Em todos os casos, pode ser adotada tanto a análise transdisciplinar, que permeia as áreas citadas, quanto a específica a cada disciplina, sendo possível, desta forma, dar maior profundidade à análise.

\section{Objetivos de ensino}

Relatando as atividades reais de um projeto concluído há poucos anos, este caso de ensino contribui para o entendimento da dinâmica de uma empresa multinacional e as barreiras enfrentadas para a implantação de uma estratégia global. Os desdobramentos verificados em todas as etapas tratam de desafios constantes nas empresas, tais como redução de custos, melhoria de processos e adoção de um novo modelo de negócios.

O estudo deste caso dará aos alunos a possibilidade 
de entender questões práticas do dia a dia das grandes empresas, facilitando a aprendizagem sobre os seguintes temas:

a. Desdobramento de uma estratégia global em uma empresa multinacional;

b. Conhecimento do modelo de Centro de Serviços Compartilhados (CSC);

c. Características e passos para a implantação de um projeto internacional;

d. Impactos de um projeto abrangendo a América Latina;

e. Abordagens para a gestão de mudanças (change management);

f. Inter-relação de diferentes disciplinas em um mesmo projeto.

\section{Sugestões de planos de aula para uso do caso}

O plano de aula para uso do caso dependerá da disciplina à qual ele será aplicado. Para cursos de Administração, seria possível propor um plano envolvendo os cinco tópicos explicitados nas tarefas sugeridas, exigindo obviamente uma sequência de aulas para esgotar os assuntos. Caso seja aplicado a uma disciplina específica, deveríamos escolher o tópico adequado e, possivelmente, a duração de uma aula seria suficiente.

De qualquer forma, uma aplicação típica passaria por compartilhar o caso com antecedência aos alunos para leitura e conhecimento prévio, com indicação das referências bibliográficas e dos temas a serem discutidos em sala de aula. Idealmente, os alunos deveriam identificar os pontos levantados e trazer suas dúvidas para construção conjunta do conhecimento. Já em sala, uma dinâmica de abertura seria aplicada para envolver os alunos.

Esta dinâmica poderia ser a formação de pelo menos dois grupos para debaterem pontos divergentes em relação a uma determinada questão, sob condução e moderação do professor. Outra sugestão de dinâmica seria atribuir a dez alunos os papéis identificados no caso para que eles debatessem as questões propostas. Em qualquer das duas dinâmicas propostas, poderia haver um terceiro grupo, observando o comportamento dos outros grupos ou dos alunos participando na dinâmica.
Partindo para o encerramento da aula, o grupo de observadores compartilharia suas anotações a respeito dos pontos discutidos e da atuação de cada participante ou grupo de participantes da dinâmica. Após este momento, os participantes poderiam também contraargumentar, enriquecendo a discussão e a construção do conhecimento. Como última atividade, o professor faria o encerramento, destacando os pontos principais e reforçando o aprendizado dos alunos.

\section{Possiveis tarefas a propor aos alunos (tópicos e sugestões de possiveis questões)}

\section{Administração de Empresas}

Debater e entender aspectos ligados à gestão de empresas na busca e implementação de estratégias que estejam alinhadas globalmente e seus impactos nas unidades de negócios locais.

\section{Estratégias Globais}

1.1. Atualmente, é possível desenvolver uma estratégia em longo prazo? Como fazêlo?

1.2. Quem deve participar da definição de uma estratégia global da empresa?

1.3. Como adotar estratégias que sejam aplicáveis a todas as unidades de negócios?

\section{Gestão de Empresas Multinacionais}

2.1. Como você vê a participação de líderes regionais na definição de uma estratégia global?

2.2. Qual a importância de administrar regionalmente um negócio?

2.3. Existem barreiras culturais em uma empresa multinacional? Explique.

\section{Melhoria de Processos}

3.1. É possível adotar processos únicos globalmente?

3.2. Em sua visão, a revisão de processos deve trazer grandes benefícios imediatos ou pequenos benefícios em longo prazo?

3.3. Qual o papel da tecnologia da informação na melhoria de processos? 


\section{Gerenciamento e Retenção de Conhecimento}

4.1. O que significa reter o conhecimento em uma organização?

4.2. Quais são os riscos de se perder o conhecimento de uma organização hoje em dia?

4.3. Como reter o conhecimento da
organização?

\section{Diretrizes para as questões propostas e discussões em Administração}

Em relação a uma visão global, as empresas enfrentam cada vez mais dificuldades de formular estratégias em longo prazo, pois a dinâmica do ambiente as obriga a realizar mudanças em suas premissas para adequar a estratégia inicialmente definida (Wittmann, Lübeck, \& Nelsis, 2013). O dinamismo dos mercados, a velocidade das transformações na sociedade e a volatilidade dos recursos estão entre os principais fatores que levam as empresas a cada vez mais concentrarem esforços na capacidade de saber capturar e entender os sinais emitidos por estes fatores e na flexibilidade de transformá-los em capacidades dinâmicas, trazendo vantagens competitivas às empresas (Teece \& Pisano, 1994). Entretanto, ela pode ser mais facilmente aplicada em relação à estrutura da organização e ao modelo de negócios (Fleischmann, Schmidt, Stary, Obermeier, \& Brger, 2014), e para isso faz-se necessário o envolvimento efetivo dos stakeholders, quaisquer que eles sejam. Em relação às barreiras culturais enfrentadas pelas empresas multinacionais, é possível observar que aquelas podem sim influenciar a capacidade de absorção destas, potencialmente diminuindo a sua capacidade de inovação (LealRodríguez, Ariza-Montes, Roldán, \& Leal-Millán, 2014).

A adoção da melhoria de processos, amparada pelas ferramentas de tecnologia da informação, resulta também em várias melhorias de desempenho, desde os benefícios da globalização até a facilitação de negócios eletrônicos (Rosemann \& vom Brocke, 2015). Outra perspectiva importante é a de que as melhorias de processo podem trazer resultados tanto em curto prazo quanto em longo prazo, dependendo dos objetivos da empresa que adota tal abordagem (Tapping \& Shuker, 2010). Finalmente, em relação à gestão e retenção do conhecimento, apesar de ser tratada como um campo complexo e fragmentado (Cherman \& Rocha-Pinto, 2013), esta abordagem ganhou maior relevância com a chegada da era da informação e também com as teorias que destacam o conhecimento como a fonte primária do rendimento econômico (Alavi \& Leidner, 2001). Portanto, reter o conhecimento pode representar uma vantagem competitiva e, para isso, a adoção de sistemas de informação, a correta documentação e atualização de processos minimizam os riscos da perda de conhecimento, a qual pode ocorrer pela saída de profissionais que levam consigo as melhores práticas ou mesmo pela insuficiência ou inexistência do registro da maneira correta como a empresa executava determinada atividade ou processo.

\section{Finanças}

Discutir aspectos da gestão financeira em uma empresa multinacional e seus desdobramentos em relação a pessoas, processos e tecnologia.

\section{Modelo de Centros de Serviços Compartilhados (CSC)}

1.1. Quais benefícios e quais prejuízos o modelo de CSC pode trazer à organização?

1.2. Qual modelo de administração de CSC você entende como o mais adequado?

1.3. É possível adotar este modelo para outras funções que não as de apoio, ou mesmo para atividades que não sejam de caráter transacional?

\section{Redução de Custos}

2.1. O que representa reduzir custo em uma empresa multinacional?

2.2. Qual ou quais alternativas se apresentam à redução de custo em uma organização?

2.3. Em um plano global de redução de custos, como tratar cada região?

\section{Controles Internos, Auditoria e Compliance}

3.1. No caso de se adotar o modelo de CSC terceirizado, a quem caberia a responsabilidade pelos Controles Internos?

3.2. Seria necessário tomar alguma ação 
especial para conduzir auditorias regulares em um CSC terceirizado?

3.3. O Código de Ética e Conduta da empresa tomadora de serviços deve ser aplicado também aos funcionários de um CSC terceirizado? Por quê?

\section{Diretrizes para as questões propostas e discussões em Finanças}

Bangemann (2005) chamou os Centros de Serviços Compartilhados como uma revolução em Finanças, não somente pelos impactos no negócio que os levavam a ser o tópico mais discutido até aquele momento, mas também porque este modelo de operação ainda continuaria a ser discutido por muito mais tempo. Os benefícios e as características já discutidos neste caso de ensino são ainda enriquecidos pela discussão a respeito dos efeitos da terceirização de atividades (Saraiva, de Andrade Soares, \& Natt, 2016), e não somente isso, mas também pela ampliação do escopo de serviços prestados pelos CSCs, chegando até mesmo a atividades de caráter analítico (Gospel \& Sako, 2010). Porém, a adoção deste modelo de negócio não pode carregar sozinha as perspectivas de redução de custos e melhoria de resultados em uma empresa. A melhor avaliação do negócio deve partir da observação das melhores oportunidades de aumentar sua lucratividade e não somente reduzir custos (Kim, Hoskisson, \& Lee, 2015), o que mostra que os fatores estratégicos de cada mercado devem ser analisados para suportar a diversificação geográfica da multinacional. Desta forma, cada região e até mesmo cada país devem ser estudados em relação às suas oportunidades de negócio.

Em relação ao impacto que a adoção do CSC traz às questões de auditoria, vale a pena enfatizar a necessidade de que os riscos à operação sejam mitigados (Amiruddin, Aman, Auzair, Hamzah, \& Maelah, 2013). A possível terceirização de atividades não exime a empresa multinacional de continuar respondendo pela exatidão de suas informações e resultados, sendo necessário para isso desenvolver um detalhado programa de prevenção, no qual as responsabilidades sejam corretamente definidas, atribuídas e formalmente comunicadas (Williford \& Small, 2013). De qualquer forma, os benefícios de um programa de controles internos, tal como definido pela Lei Sarbannes-Oxley (Wagner \& Dittmar, 2006), devem ser complementados pelo treinamento e conscientização de todos os envolvidos nas transações financeiras de tal forma que não somente uma formalidade seja cumprida em relação às atitudes dos funcionários da multinacional, mas também para que a conscientização em relação aos direitos e obrigações seja transmitida aos terceiros prestadores de serviços (Adam \& Rachman-Moore, 2004).

\section{Gerenciamento de Projetos}

Tratar das práticas de gerenciamento de projetos multidisciplinares em um contexto de empresas multinacionais ou de projetos globais.

\section{ComposiçãodeEquipes Multidisciplinares}

1.1. Quais características a observar na constituição de uma equipe multidisciplinar?

1.2. Como conduzir esta equipe e mantê-la equilibrada?

1.3. No caso apresentado, faltou alguma habilidade ou característica no grupo formado?

\section{Projetos Globais em Empresas} Multinacionais

2.1. Existem benefícios na implantação de um projeto estratégico global?

2.2. Quais são as dificuldades para a implantação de um projeto estratégico global?

2.3. Como tratar unidades de negócios de tamanhos diferentes dentro de um mesmo projeto global?

\section{Projetos Compartilhados}

3.1. Como obter sucesso na condução de um projeto onde os interesses aparentemente são antagônicos?

3.2. É possível tomar proveito das lições aprendidas em outros projetos? Como?

3.3. Para o sucesso de um projeto compartilhado, qual seria a documentação necessária? 


\section{Diretrizes para as questões propostas e discussões em Gerenciamento de Projetos}

As chances de sucesso de um projeto são aumentadas a partir da seleção de um líder que tenha tanto o conhecimento técnico quanto as habilidades administrativas para conduzir o projeto até seu final (Belassi \& Tukel, 1996). Desta forma, podemos entender que uma equipe de sucesso deverá ser composta não somente por aqueles que possuem características complementares, mas preferencialmente por integrantes que possam ir além de suas características técnicas, possuindo também as habilidades de relacionamento pessoal e trabalho em equipe. Outro fator importante é a identificação coletiva entre os membros da equipe, o que favorece o aprendizado, o equilíbrio e o seu desempenho (Van Der Vegt \& Bunderson, 2005), bem como a criação de uma visão de futuro para minimizar a resistência à mudança (Ceribeli \& Merlo, 2013).

A adoção de estratégias globais, e consequentemente de projetos globais, é cada vez mais comum nas grandes multinacionais, isso para aproveitar as oportunidades que se apresentam e também para se beneficiar da cadeia de valor e das capacidades ou recursos que existam em determinados países ou regiões (Lasserre, 2012). Para contornar as dificuldades relacionadas às diferenças culturais entre os países, aos interesses políticos dentro da própria organização e também às dificuldades inerentes aos processos de comunicação, a implementação de um projeto global deve levar em conta as particularidades de cada mercado e como elas se refletem na própria organização.

Outro ponto a ser destacado refere-se à importância da criação de espaços de socialização entre as equipes que participam de um projeto compartilhado (Kotlarsky \& Oshri, 2005). É nele que as sinergias entre os membros das equipes são criadas e potencializadas, mas principalmente a confiança é exercitada permitindo que as barreiras da cultura e de interesses próprios sejam vencidas (Govindarajan \& Gupta, 2001). Desta forma, a confiança existente entre os membros da equipe e a visão de objetivos comuns são a resposta a objetivos que possam ser aparentemente antagônicos.

A criação de uma mentalidade de trabalho em equipe e um ambiente de colaboração são suportados também pela documentação do projeto, e os arquivos técnicos a ele relacionados permitem registrar as lições aprendidas e também as mudanças que ocorreram em qualquer fase. A guarda desta documentação pode ser feita através de meios físicos ou eletrônicos, sendo que, em qualquer situação, elas não deve ficar isolada, mas pelo contrário, deve ser de fácil acesso e estar integrada ao dia a dia principalmente da liderança do projeto (Joia, 1998).

\section{Recursos Humanos}

Conversar e assimilar os conceitos e práticas que tocam RH na gestão de projetos multidisciplinares em empresas multinacionais.

\section{A Escolha de Profissionais para Projetos}

1.1. Quais as características mais importantes, pela ordem, na escolha de profissionais para um projeto global multidisciplinar?

1.2. No caso estudado, quais seriam os desafios a administrar, sob o ponto de vista de RH, na composição e atuação do grupo?

1.3. Ainda no caso, até que ponto a habilidade em gerenciamento de projetos era necessária a todos os componentes da equipe multidisciplinar?

\section{Gerenciamento de Mudanças}

2.1. Quais os impactos a administrar nos países afetados pela migração de atividades financeiras ao CSC terceirizado?

2.2. Quais seriam as ações de $\mathrm{RH}$ para minimizar estes impactos citados por você?

2.3. Na sua visão, qual seria o pior destes impactos? Explique.

\section{A Importância da Comunicação Corporativa}

3.1. Você teria incluído um profissional de comunicação no grupo de trabalho que conduziu o caso estudado? Por quê?

3.2. Cite pelo menos três tipos de audiências envolvidas no projeto do caso estudado. Com qual frequência deveriam ser informadas?

3.3. Quais seriam as mensagens-chave a transmitir às unidades de negócios no início do projeto? 


\section{Diretrizes para as questões propostas e discussões em Recursos Humanos}

O Gerenciamento de Recursos Humanos pode ser entendido como um dos processos mais importantes em uma empresa orientada a projetos, impactando diretamente como ela contrata e utiliza os profissionais que nela trabalham (Huemann, Keegan, \& Turner, 2007). Além disso, o gerenciamento de projetos demanda uma mescla de capacidades pessoais, tais como as habilidades técnicas, as de gerenciamento e as de liderança, o que devemos reconhecer, é difícil encontrar em uma mesma pessoa (Crawford, 2014), isso sem falarmos do domínio de diferentes idiomas para que a comunicação seja eficaz tanto com a direção da multinacional quanto com a equipe que o implementa.

Projetos desta magnitude exigem que a abordagem da gestão da mudança dirija seu foco às estruturas da empresa, às práticas de gerenciamento e aos processos e sistemas da organização, elementos estes, que impactam o clima organizacional, comprometendo a motivação e o desempenho tanto da unidade de negócios quanto também no nível de cada indivíduo que a compõe (J. Hayes, 2014). Por outro lado, além dos efeitos negativos que a terceirização normalmente traz como, por exemplo, a alta rotatividade e o desemprego (Saraiva et al., 2016), ela também gera baixa estima naqueles que permanecem na organização.

A evolução da comunicação corporativa nas últimas décadas levou-a do simples papel de relações públicas, gerindo a comunicação com os principais stakeholders notadamente através da imprensa, a uma função estratégica que agrupa distintas habilidades para atender toda a organização, cuidando tanto do público externo quanto também do público interno (Cornelissen, 2014). Exercendo sua nova função estratégica, a comunicação corporativa entendeu que o diálogo com empregados e clientes é mais relevante do que a função exercida anteriormente, principalmente por utilizar diferentes meios (Sinha \& Bhatia, 2016). Ainda segundo estes autores, a relação entre mensagens, meios e audiência permite desenvolver e implementar estratégias efetivas de comunicação corporativa.

\section{Tecnologia da Informação}

Discorrer sobre o papel da área de Tecnologia de Informação (TI) em um projeto estratégico de uma empresa multinacional.

\section{O Apoio de TI às Áreas de Negócios}

1.1. No seu dia a dia (profissional ou pessoal), qual a visão que você tem do nível de satisfação dos clientes ou das áreas de negócio em relação ao suporte dado por TI?

1.2. No caso estudado, identifique pelo menos três níveis de interação do profissional de TI do grupo multidisciplinar do projeto.

1.3. Por que foi necessário fazer um levantamento das aplicações que estavam em uso?

\section{Segurança da Informação}

2.1. Você deixaria um terceiro ingressar em seus sistemas financeiros? Caso seja obrigado, o que faria para minimizar os riscos de perda de informações?

2.2. Quem deveria ser responsável pelo controle de acesso aos sistemas da empresa? As áreas de TI da empresa, os líderes de finanças ou o terceiro? Justifique.

2.3. Como você administraria a troca de operadores de um CSC que devem acessar as bases de dados existentes dentro de sua empresa? Seria possível algum tipo de controle?

\section{Sistemas de Gestão de Informação}

3.1. A seu ver, por que existiam tantas aplicações e sistemas de informação nas unidades de negócios da América Latina?

3.2. Comente os benefícios da utilização de um sistema único (ERP) nos países de qualquer região de negócios.

3.3. Qual seria a sua decisão? Implantar primeiro o ERP e depois o CSC, ou primeiro o CSC e depois o ERP? Explique. 


\section{Diretrizes para as questões propostas e discussões em Tecnologia da Informação (TI)}

A Tecnologia da Informação (TI) é vista como uma importante ferramenta para a obtenção de vantagem competitiva, sendo que, para mantê-la, é necessário que as empresas continuem fazendo significativos investimentos em infraestrutura (Liu, Ke, Wei, \& Hua, 2013). Por outro lado, em função desta importância, os profissionais que trabalham em TI se veem no centro das atenções e, por isso, não raro, são chamados por todos os níveis da organização, seja operação seja administração, fazendo com que seu nível de interação e exposição seja alto e demande não somente as habilidades técnicas, mas também as habilidades de um bom relacionamento pessoal (Byrd \& Turner, 2001).

A segurança de um sistema de informação deve, por princípio, proteger a confidencialidade, a integridade e a disponibilidade do sistema e, por isso, considerando a intensidade das informações que suporta a moderna economia apoiada na Internet, é fácil entender porque a segurança da informação é um dos principais gastos das empresas, seja em softwares para a detecção de vírus, barreiras de acesso (firewalls), técnicas robustas de criptografia, sistemas de detecção de invasão de rede e backup automatizado de dados (Gordon \& Loeb, 2002).

No aspecto de suporte ao negócio, o sistema ERP é um sistema de informação padronizado, utilizado na execução de processos de negócio e que permite a integração de boa parte da empresa, pois abrange dados e processos, trazendo agilidade e flexibilidade organizacional, facilitando a tomada de decisão e melhorando a qualidade e a eficiência da empresa (Rainer, Cegielski, Splettstoesser-Hogeterp, \& SanchezRodriguez, 2013). Apesar de seu sucesso, ainda são enfrentados problemas na sua implantação não somente pela sua complexidade, mas também porque ela normalmente demanda significativas reorganizações na estrutura das empresas (Wortmann, 1998).

\section{Fontes dos dados}

A preparação do caso foi feita com dados levantados pelo próprio pesquisador em um trabalho de pesquisaação (Action Research), uma vez que, além de participar diretamente no projeto, teve também o apoio de outros profissionais para a implantação dele.
A participação direta do pesquisador nas reuniões de definição do projeto na América Latina, bem como o acesso e a consulta a atas de reunião das definições tomadas no nível global, foi corroborada pelo acesso a documentos elaborados para a preparação e implantação do plano de gerenciamento de mudanças.

Outras fontes de dados secundárias foram as definições de responsabilidades dos membros do projeto, bem como o plano de implantação preparado para cada grupo de países.

\section{Sugestões de bibliografia e referências}

Adam, A. M., \& Rachman-Moore, D. (2004). The methods used to implement an ethical code of conduct and employee attitudes. Journal of Business Ethics, 54(3), 225-244.

Alavi, M., \& Leidner, D. E. (2001). Review:

Knowledge management and knowledge management systems: Conceptual foundations and research issues. MIS Quarterly, 107-136.

Amiruddin, R., Aman, A., Auzair, S. M., Hamzah, N., \& Maelah, R. (2013). Mitigating risks in a shared service relationship: The case of a Malaysian bank. Qualitative Research in Accounting and Management, 10(1), 78-93.

Bangemann, T. O. (2005). Shared services in finance and accounting. Gower Publishing, Ltd.

Belassi, W., \& Tukel, O. I. (1996). A new framework for determining critical success/failure factors in projects. International Journal of Project Management, 14(3), 141-151.

Bergeron, B. (2003). Essentials of Shared Service Centers. Hoboken, NY: John Wiley \& Sons.

Byrd, T. A., \& Turner, D. E. (2001). An exploratory analysis of the value of the skills of IT personnel: Their relationship to IS infrastructure and competitive advantage. Decision Sciences, 32(1), 21-54.

Ceribeli, H. B., \& Merlo, E. M. (2013). Mudança organizacional: um estudo multicasos. Revista Pensamento Contemporâneo em Administração, 7(2), 134154.

Cherman, A., \& Rocha-Pinto, S. R. (2013). Gestão do conhecimento no Brasil: visão da academia. Revista Pensamento Contemporâneo em Administração, 7(1), 92-107. 
Cornelissen, J. (2014). Corporate Communication: $A$

Guide to Theory and Practice. SAGE.

Crawford, J. K. (2014). Project Management Maturity Model. CRC Press.

Fleischmann, A., Schmidt, W., Stary, C., Obermeier, S., \& Brger, E. (2014). Subject-oriented business process management. Springer Publishing Company, Incorporated.

Gordon, L. A., \& Loeb, M. P. (2002). The economics of information security investment. $A C M$

Transactions on Information and System Security (TISSEC), 5(4), 438-457.

Gospel, H., \& Sako, M. (2010). The unbundling of corporate functions: the evolution of shared services and outsourcing in human resource management. Industrial and Corporate Change, 19(5), 1367-1396.

Govindarajan, V., \& Gupta, A. K. (2001). Building an effective global business team. MIT Sloan Management Review, 42(4), 63.

Hayes, B. (2007). Shared services in local government: Improving service delivery: By Ray Tomkinson. International Journal of Leadership in Public Services, 3(4), 73-76.

Hayes, J. (2014). The theory and practice of change management. Palgrave Macmillan.

Huemann, M., Keegan, A., \& Turner, J. R. (2007). Human resource management in the project-oriented company: A review. International Journal of Project Management, 25(3), 315-323.

Janssen, M., \& Joha, A. (2006). Motives for Establishing Shared Service Centers in Public Administrations. International Journal of Information Management, 26, 102-116.

Joia, L. A. (1998). Large-scale reengineering in project documentation and workflow at engineering consultancy companies. International Journal of Information Management, 18(3), 215-224.

Kim, H., Hoskisson, R. E., \& Lee, S.-H. (2015). Why strategic factor markets matter:"New" multinationals' geographic diversification and firm profitability. Strategic Management Journal, 36(4), 518-536.

Kotlarsky, J., \& Oshri, I. (2005). Social ties, knowledge sharing and successful collaboration in globally distributed system development projects.
European Journal of Information Systems, 14(1), 37-48.

Lasserre, P. (2012). Global strategic management. Palgrave Macmillan.

Leal-Rodríguez, A. L., Ariza-Montes, J. A., Roldán, J. L., \& Leal-Millán, A. G. (2014). Absorptive capacity, innovation and cultural barriers: A conditional mediation model. Journal of Business Research, 67(5), 763-768.

Liu, H., Ke, W., Wei, K. K., \& Hua, Z. (2013). The impact of IT capabilities on firm performance: The mediating roles of absorptive capacity and supply chain agility. Decision Support Systems, 54(3), 14521462 .

Quinn, B., Cooke, R., \& Kris, A. (2000). Shared Services: Mining for Corporate Gold. Financial Times: Prentice Hall.

Rainer, R. K., Cegielski, C. G., SplettstoesserHogeterp, I., \& Sanchez-Rodriguez, C. (2013). Introduction to information systems: Supporting and transforming business. John Wiley \& Sons.Rosemann, M., \& vom Brocke, J. (2015). The six core elements of business process management. In Handbook on Business Process Management 1 (p. 105-122). Springer.

Saraiva, L. A. S., de Andrade Soares, C. B., \& Natt, E. D. M. (2016). Representações Sociais De Relações De Trabalho: Um Estudo Com Trabalhadores Primarizados/Social Representations of Work Relations: A Study with Reinsourcing Workers. Revista Pensamento Contemporâneo em Administração, 10(1), 36.

Schulman, D., Harmer, M., \& Lusk, J. (2001). Shared Services: agregando valor às unidades de negócios. São Paulo: Makron Books.

Schwarz, G., \& Mechling, J. (2007). Shared service center. RAR-103, Kennedy School of Government, Harvard University.

Sinha, M., \& Bhatia, P. (2016). Strategic corporate communication and impact in Indian service sector. Corporate Communications: An International Journal, 21(1), 120-140.

Tapping, D., \& Shuker, T. (2010). Lean Office: Gerenciamento do fluxo de valor para áreas administrativas-8 passos para planejar, mapear e sustentar melhorias Lean nas áreas administrativas. São Paulo: Leopardo Ed. 
Teece, D., \& Pisano, G. (1994). The dynamic capabilities of firms: an introduction. Industrial and Corporate Change, 3(3), 537-556.

Van Der Vegt, G. S., \& Bunderson, J. S. (2005).

Learning and performance in multidisciplinary teams: The importance of collective team identification. Academy of Management Journal, 48(3), 532-547.

Wagner, S., \& Dittmar, L. (2006). The unexpected benefits of Sarbanes-Oxley. Harvard Business Review, 84(4), 133.

Williford, K., \& Small, K. (2013). Establishing an Effective Compliance Program: An Overview to Protecting Your Organization. Recuperado em 13 de junho de 2016, de http://www.acc.com/ legalresources/quickcounsel/eaecp.cfm?makepdf $=1$

Wittmann, M. L., Lübeck, R. M., \& Nelsis, V. D. M. (2013). Uma Visão Não-Linear Sobre Estratégia Empresarial pelo Prisma da Complexidade/A Non-Linear View Of Business Strategy Through The Prism Of Complexity. Revista Pensamento Contemporâneo em Administração, 7(4), 117.

Wortmann, J. C. (1998). Evolution of ERP systems. In Strategic Management of the Manufacturing Value Chain (p. 11-23). Springer. Recuperado em 13 de junho de 2016, de http:/ /link.springer.com/ chapter/10.1007/978-0-387-35321-0_2. 